\title{
The Effects of the Time Lag in the Activation of Atmospheric Ice Nuclei on the Number of Ice Crystals in Cloud
}

\author{
By Takao Takeda \\ Water Research Laboratory Nagoya University \\ (Manuscript received 6 July 1967)
}

\begin{abstract}
The influence of the time lag in the activation of ice nuclei on the number of ice crystals in cloud was numerically studied. Following conclusions were obtained from computation; (1) the increase in the number of activated atmospheric ice nuclei with cooling-time is remarkable, particularly under the cooling at lower temperature than $-25^{\circ} \mathrm{C}$. The total number of atmospheric ice nuclei activated for a few hours under the cooling at $-30^{\circ} \mathrm{C}$ to $-40^{\circ} \mathrm{C}$ becomes 10 times as large as that for 1 minutes, while the number of activated atmospheric ice nuclei in the case of the cooling at the temperature warmer than $-20^{\circ} \mathrm{C}$ is at most 3 times as large even after 10 hours as that for 1 minute. (2) The number of atmospheric ice nuclei activated in the upward air-current with vertical velocity of the order of $10 \mathrm{~cm} / \mathrm{s}$ is 5 to 10 times as large as that in the air-current of the order of $10 \mathrm{~m} / \mathrm{s}$, if the numbers in both cases are compared at the same level.
\end{abstract}

\section{Introduction}

It has often been said that the number density of ice crystals observed in the cloud by an air plane is larger than the one expected from that of atmospheric ice nuclei. Koenig (1963) and Braham (1964) observed in "Project White Top" that the concentration of ice pellets which exist in the cloud at the temperature warmer than $-10^{\circ} \mathrm{C}$ was not related to the concentration of atmospheric ice nuclei at the ground level. Takeda (1967) showed, by computing the freezing-probability of supercooled water drops due to the collision of ice crystals formed on ice nuclei with drops and the growth rate of solid precipitation particles, that the computationally obtained probability of the formation of frozen drops which were able to become graupels was about $10 \%$ of that inferred from observations, if the number density of atmospheric ice nuclei measured in a cold box was adopted in computation. He stated that this disagreement could be the existence of larger number density of ice crystals than the one expected from that of atmospheric ice nuclei measured in a cold box.

Several attempts have been made to account for unexpectedly large number density of ice crystals in the real cloud. For example, Braham (1964) and Koenig (1963, 1966) suggested that their observations were interpretted well by invoking the measurements of droplet splintering of Mason and Maybank (1960).

However, it is questionable to apply the number density of atmospheric ice nuclei measured in a cold box to the real cloud in which ice nuclei are cooled for much longer time than in the cold box, because the activation of one ice nucleus is a statistical process and the possibility of the ice-formation on the ice nucleus may increase with time. The increase of the total number of activated ice nuclei with time of cooling is experimentally verified. Vonnegut (1949) showed that ice crystals were still being formed on $\mathrm{AgI}$ smoke in supercooled cloud 50 minutes even after the experiment began. Warner and Newnham (1958) stated that the total number of activated atmospheric ice nuclei increased with time, with a time constant of about 6 minutes. Fletcher (1958) showed that the results obtained by Warner and Newnham were consistent with the ones predicted from the theory of heterogeneous nucleation. These facts mean that even an ice nucleus which did not become activated 
under the cooling at a certain temperature in a cold box has a possibility of activating at the same temperature if it is cooled for sufficiently long time. In other words, time lag exists in the activation of an ice nucleus.

In this paper, the auther describes the influences of the time lag in the activation of atmospheric ice nuclei on the number density of ice crystals in the cloud in which ice nuclei are cooled for a longer time than in a cold box.

\section{The theory of the activation of atmo- spheric ice nuclei}

The activation probability $(\alpha)$ of an atmospheric ice nucleus under the cooling at temperature $T$ is given by the rate of production of critical embryos on the ice nucleus. From the theory of heterogeneous nucleation from a supersaturated vapor, it is expressed as follows (see Fletcher, 1962);

$$
\begin{gathered}
\alpha=A \cdot n^{\prime} \cdot 4 \pi r^{2} \cdot \exp \left(\frac{\Delta G^{*}}{k T}\right) \\
A=\frac{P}{(2 \pi m k T)^{1 / 2}} \pi r^{* 2}
\end{gathered}
$$

where $A$ is the number of water molecules which a critical embryo gains for unit time through the collision with surrounding water vapor molecules, $n^{\prime}$ is the number of single molecules absorbed on unit area surface of the ice nucleus and $\Delta G^{*}$ is the free energy required to form a critical embryo. Here,

$r$ : the radius of an ice nucleus.

$P$ : ambient water vapor pressure.

$m$ : the mass of water vapor molecule.

$T$ : ambient temperature.

$\pi r^{* 2}$ : the surface area of a critical embryo on an ice nucleus ( $r^{*}$ is the curvature radius of the embryo).

The value of $A \cdot n^{\prime}$ is known to be between $10^{24}$ and $10^{27}$ in the unit of $\left(\mathrm{cm}^{2} \mathrm{~s}\right)^{-1}$.

According to the nucleation theory at water saturation (Dunning 1955),

$$
\frac{\Delta G^{*}}{k T}=\frac{16 \pi \sigma^{3} v^{2}}{3 k^{3} T^{3}} f\left(\log \frac{P_{L}}{P_{S}}\right)^{-2}
$$

Here,

$\sigma:$ ice-vapor surface free energy.

$v$ : the volume occupied by an ice molecule.

$P_{L}$ : the saturation water vapor pressure over water.

$P_{S}$ : the saturation water vapor pressure over ice.

$f$ depends on the properties of the ice-nucleus interface.

The value of $\alpha$ in any ice nucleus increases with the decrease in ambient temperature. The temperature $T_{0}{ }^{j}$ at which the value of $\alpha$ of a certain ice nucleus is equal to unity is defined to be a threshold temperature of the ice nucleus. $j$ means that all of ice nuclei belonging to $j$ group have a threshold temperature of $T_{0}{ }^{j}$ (in other words, it takes 1 second on the average for these ice nuclei to become activated).

Let us deduce the activation probability $\left(\alpha^{j}\left(T_{0}{ }^{j}, T\right)\right)$ of an ice nucleus of $j$ group at temperature $T$. Since the logarithmic term in equation (3) can be generally approximated to be proportional to the degree of supercooling (that is, $\log \left(P_{L} / P_{S}\right) \approx C_{1} \Delta T$ ), equation (3) becomes

$$
\begin{gathered}
\frac{\Delta G^{*}}{k T}=C_{2} \frac{1}{T^{3} \Delta T^{2}} \\
C_{2} \equiv \frac{16 \pi \sigma^{3} v^{3}}{3 k^{3}} f C_{1}
\end{gathered}
$$

As $\alpha^{j}$ is equal to 1 at temperature $T_{0}{ }^{j}$,

$$
A n^{\prime} 4 \pi r^{2} \exp \left[-C_{2} \frac{1}{\left(T_{0}\right)^{3}\left(\Delta T_{0}{ }^{j}\right)^{2}}\right]=1
$$

From equations (4) and (5)

$$
\begin{gathered}
\alpha^{j}\left(T_{0}^{j}, T\right)=A \cdot n^{\prime} 4 \pi r^{2} \exp \left[-\beta\left(\frac{T_{0}{ }^{j}}{T}\right)^{3}\left(\frac{\Delta T_{0}{ }^{j}}{\Delta T}\right)^{2}\right] \\
\beta \equiv \log _{e}\left(A n^{\prime} 4 \pi r^{2}\right)
\end{gathered}
$$

can be obtained. When this ice nucleus is cooled at the temperature warmer than $T_{0}{ }^{j}$, $\alpha^{j}$ is smaller than 1 and it takes a long time for the nucleus to be activated.

Fig. 1 shows the activation probabilities of ice nuclei which are cooled at the temperature warmer than their threshold temperatures. The value of $A \cdot n^{\prime} \cdot 4 \pi r^{2}$ is taken to be $3.14 \times$ $10^{16} \mathrm{sec}^{-1}$. Ordinate and abscissa are the activation probability and the threshold temperature. $\alpha_{n}(n=1,2, \cdots \cdots)$ means the activation probability of an ice nucleus which is cooled at the warmer temperature by $n^{\circ} \mathrm{C}$ than the 


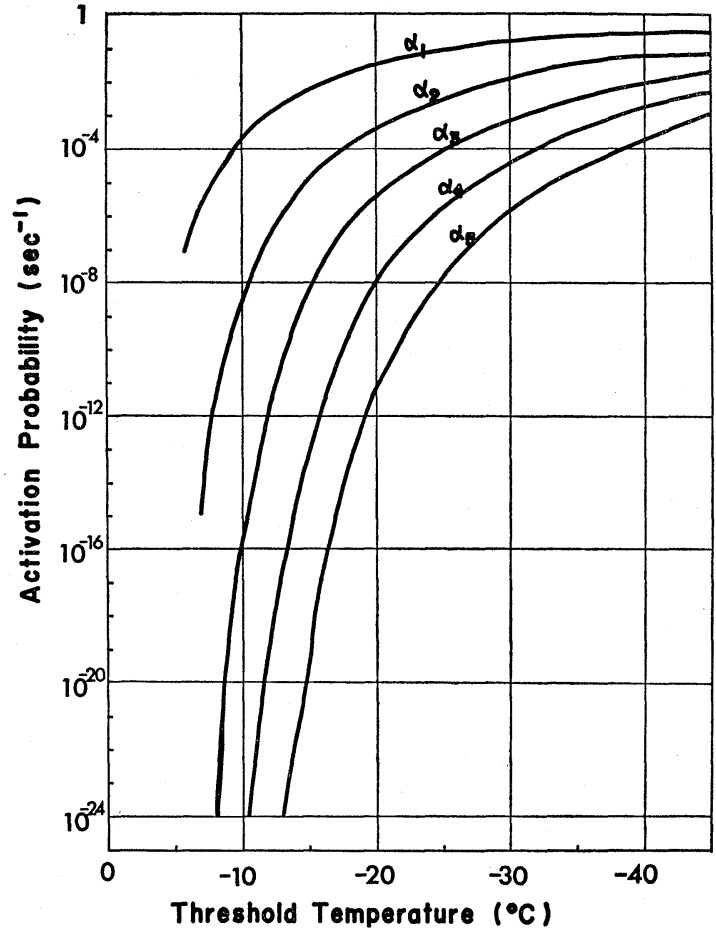

Fig. 1. Activation probabilities $\left(\alpha_{n}\right)$ of ice nuclei which are cooled at warmer temperature by $n^{\circ} \mathrm{C}$ than their threshold temperature. The value of $A \cdot n^{\prime} \cdot 4 \pi r^{2}$ is $3.14 \times 10^{16} \mathrm{sec}^{-1}$.

threshold temperature of the nucleus. For example, it is seen from the figure that when an ice nucleus with threshold temperature of $-25^{\circ} \mathrm{C}$ is cooled at $-20^{\circ} \mathrm{C}$, its activation probability is about $10^{-8} \mathrm{sec}^{-1}$ and it cannot be activated until it is cooled for $10^{8}$ seconds (in other words, one of $10^{8}$ nuclei with threshold temperature of $-25^{\circ} \mathrm{C}$ can be activated for one second at $-20^{\circ} \mathrm{C}$ ). The activation probabilities of ice nuclei with high threshold temperature become very small at the warmer temperature and they cannot be activated even after the cooling of considerably long time. However, the probabilities of ice nuclei with low threshold temperature do not become very small at the warmer temperature and they can be active as long as they are sufficiently cooled.

In all of computations shown in Fig. 1, the value of $A \cdot n^{\prime} \cdot 4 \pi^{2}$ was taken to be $3.14 \times 10^{16}$ $\mathrm{sec}^{-1}$. Strictly speaking, this value changes depending upon ambient temperature, the size of an ice nucleus and the exact process of nucleation. However, as seen from Fig. 1,

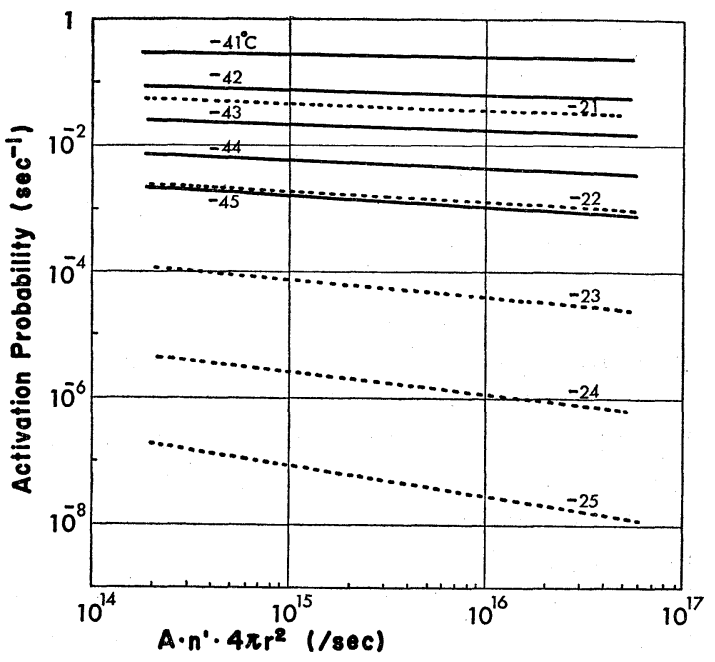

Fig. 2. Effect of $A \cdot n^{\prime} \cdot 4 \pi r^{2}$ on the activation-probability. Solid and dotted lines indicate the cases under the cooling at $-40^{\circ} \mathrm{C}$ and $-20^{\circ} \mathrm{C}$, respectively. Figures besides curves mean threshold temperatures.

the expected change in its value is considered to be much smaller than that in $\exp \left(\Delta G^{*} / k T\right)$ originated from the change in ambient temperature. Fig. 2 shows the effect of the value of $A \cdot n^{\prime} \cdot 4 \pi r^{2}$ on the activation probability. The ordinate and abscissa are the activation probability and the value of $A \cdot n^{\prime} \cdot 4 \pi r^{2}$, respectively. Solid or dotted lines indicate the cases under the cooling at $-40^{\circ} \mathrm{C}$ or $-20^{\circ} \mathrm{C}$. Figures besides curves mean the threshold temperature of ice nuclei. It is clear that the effect which the change by $1^{\circ} \mathrm{C}$ in the difference between the threshold temperature and ambient temperature gives on the value of $\alpha$ through the term of $\exp \left(-\Delta G^{*} / k T\right)$ is much larger than that of the change by one order in $A$. $n^{\prime} \cdot 4 \pi r^{2}$.

When atmospheric ice nuclei with threshold temperature of $T_{0}{ }^{j}$ and with the number density of $N_{0}^{j}$ are cooled at temperature $T$, the number $\left(N^{j}\right)$ of ice nuclei which are activated in air parcel of unit volume for $t$ seconds is given by

$$
N^{j}=\int_{0}^{t} \frac{d N^{j}}{d t} d t=\int_{0}^{t}\left(N_{0}^{j}-N^{j}\right) \alpha^{j}\left(T_{0}^{j}, T\right) d t
$$

or

$$
N^{j}=N_{0}^{j}\left[1-\exp \left(-\alpha^{j} t\right)\right]
$$

The number density (n) of atmospheric ice 
nuclei activated at warmer temperature than $T$ is given by familiar empirical formula (ex. Mossop, 1963)

$$
n=n_{0} \exp \left[\gamma^{\prime}(273-T)\right]
$$

where the value of $\gamma^{\prime}$ is between 0.4 and 0.8 with typical value of $0.6 . n_{0}$ is more variable, typically being about $10^{-5} /$ litre, with variations of several orders of magnitude sometimes occurring. Strictly speaking this formula expresses the number density of atmospheric ice nuclei activated as a result of cooling for a few to 20 minutes. Therefore the influences of the time lag in the activation of ice nuclei are included in it. It is assumed however, that the number density of atmospheric ice nuclei with warmer threshold temperature than $T\left(\sum_{T_{0}{ }^{j} \geqq T} N_{0}{ }^{j}\right)$ can be also expressed by similar formula with the one mentioned above. That is,

$$
\sum_{T_{0} j_{\geqq T}} N_{0}^{j}=N_{0} \exp [r(273-T)]
$$

This assumption may be admittable because the purpose of numerical computations is to study quantitatively the effects that the time lag in the activation of ice nuclei gives on the number density of ice crystals formed on these atmospheric ice nuclei. In this paper the values of $\gamma$ and $N_{0}$ are taken to be 0.6 and $10^{-5} /$ litre, respectively. $N_{0}{ }^{j}$ is obtained by differentiating equation $\left(8^{\prime}\right)$.

The number density $\left(N_{t}\right)$ of atmospheric ice nuclei which become activated for $t$ seconds under the cooling at temperature $T$ is given by summing above mentioned $N^{j}$ over all values of $j$, that is,

$$
N_{t}=\sum_{j} N^{j}
$$

$N_{t}$ is divided into following two groups

$$
\begin{array}{cc}
N_{t}=N_{1}+N_{2} & \\
N_{1}=\sum_{j} N_{0}^{j}\left[1-\exp \left(-\alpha^{j} t\right)\right] & T \leqq T_{0}{ }^{j} \\
N_{2}=\sum_{j} N_{0}^{j}\left[1-\exp \left(-\alpha^{j} t\right)\right] & T>T_{0}^{j}
\end{array}
$$

$N_{1}$ corresponds to atmospheric ice nuclei with higher threshold temperature than cooling temperature $T$ and they can be activated in very short time because their activation- probability is larger than unity. Atmospheric ice nuclei belonging to $N_{2}$ have lower threshold temperatures than $T$ and their probability is less than unity. Since the values of $\alpha$ in the latter group are generally negligibly smaller than $1, N_{2}$ is considered to be roughly equal to $\left(\sum_{j} N_{0}^{j} \cdot \alpha^{j}\right) \cdot t$. This means that the number of activated ice nuclei in the $N_{2}$-group increases approximately in proportion to cooling time. Hereafter atmospheric ice nuclei belonging to $N_{1^{-}}$and $N_{2}$-group are called to be "fast-" and "slow-nuclei", respectively. Whether a certain atmospheric ice nucleus belongs to "fast nuclei" or "slow nuclei" is determined by cooling-temperature and its threshold temperature.

Equations (6), (7), (8)' and (10) being used, the changes with time in the number density of activated atmospheric ice nuclei can be numerically studied.

\section{Results of numerical computations on the number of atmospheric ice nuclei activated under the cooling at constant temperature $(d T / d t=0)$.}

In this chapter shown are results of numerical computations concerned with the number density of atmospheric ice nuclei which are activated under the cooling at constant temperature with an assumption that $A \cdot n^{\prime} \cdot 4 \pi r^{2}$ $=3.14 \times 10^{16} \mathrm{sec}^{-1}$.

Fig. 3 shows the change with time in the

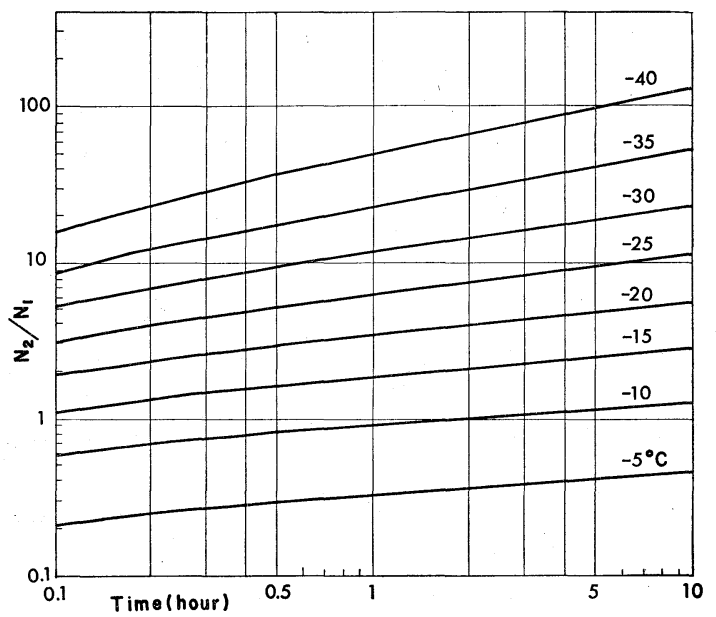

Fig. 3. Change with time in the ratio of the number of activated slow nuclei to that of fast nuclei. Figures besides curves are cooling-temperature. 
ratio of the number density of slow ice nuclei which are activated under the cooling at constant temperature to that of fast ice nucli at the temperature. Ordinate and abscissa are the ratio of $N_{2}$ to $N_{1}$ and cooling-time. Figures besides curves indicate cooling-temperature. It can be clearly seen from the figure that the increase with time in the number of activated slow nuclei is remarkable particularly in the cases of low cooling temperature.

When atmospheric ice nuclei are cooled at $-10^{\circ} \mathrm{C}$, the number of activated slow nuclei becomes comparable with that of fast nuclei after 1 hour. However, under the cooling at warmer temperature than $-20^{\circ} \mathrm{C}$ the increase

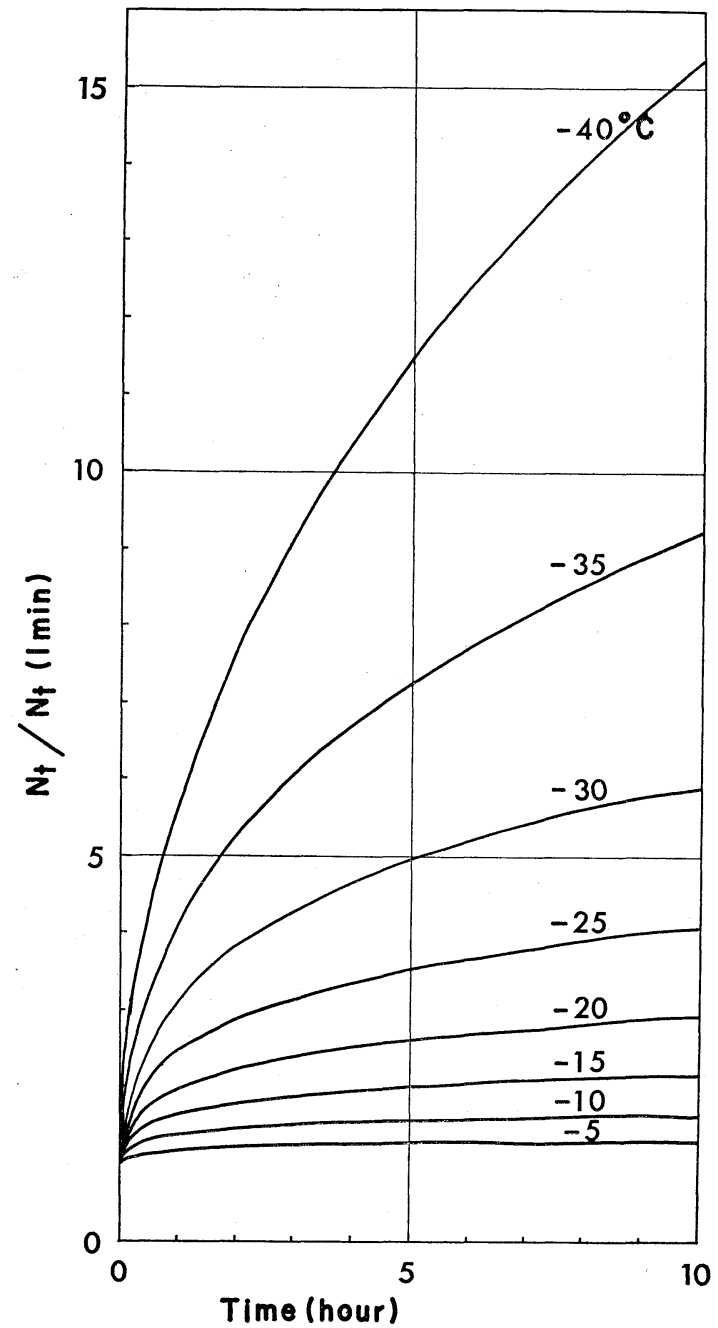

Fig. 4. Change with time in the ratio of the total number $\left(N_{t}\right)$ of activated ice nuclei to $N_{t}$ (1 $\min$ ). with time in the number of activated slow nuclei is very weak between 1 hour and 10 hours. In the case of $-30^{\circ} \mathrm{C}$ in cooling temperature, the number of activated slow nuclei is 10 times as large as that of fast nuclei after 30 minutes and it increases considerably with time even after 1 hour. In the case of $-40^{\circ} \mathrm{C}$, slow nuclei 100 times more than fast nuclei are activated after 6 hours.

In Fig. 4 shown is the change with time in the ratio of the total number $\left(N_{t}\right)$ of atmospheric ice nuclei which are activated under the cooling of constant temperature to the total number $\left(N_{t}(1 \mathrm{~min})\right)$ of those which are activated for 1 minutes at that temperature. Ordinate is the ratio of $N_{t}$ to $N_{t}(1 \mathrm{~min})$.

When ice nuclei are cooled at $-10^{\circ} \mathrm{C}$, the total number of ice nuclei activated for 10 hours cannot become even twice as large as $N_{t}(1 \mathrm{~min})$. Under the cooling at $-20^{\circ} \mathrm{C}, N_{t}$ for 10 hours is at most three times as large as $N_{t}(1 \mathrm{~min})$. However, in the case of $-30^{\circ} \mathrm{C}$, $N_{t}$ for 5 hours is five times as large as $N_{t}$ (1 $\mathrm{min})$. In the case of $-40^{\circ} \mathrm{C} N_{t}$ for 3.5 hours becomes 10 times as large as $N_{t}(1 \mathrm{~min})$ and $N_{t}$ for 9.5 hours does 15 times. Thus the increase with time in the number of activated atmospheric ice nuclei is very remarkable in the case of the cooling at low temperature.

These results mean that the temperature spectrum on the activation of atmospheric ice nuclei may change with cooling time. Fig. 5 indicates the change with cooling time in the temperature spectrum on the activation of atmospheric ice nuclei. Ordinate is the total number of atmospheric ice nuclei activated under the cooling at warmer temperature than the temperature shown by abscissa. Figure besides each curve means cooling time, which is 1 second, 2 hours or 10 hours. The total number of activated ice nuclei changes with time particularly in low temperature. The change with time in the gradient of spectrum curve is shown in Fig. 6, in which ordinate is the value of $\gamma$ in equation (8). The value of $\gamma$, which was taken to be 0.6 initially, varies rapidly during 1 hour and it becomes mere than 0.7 after 1 hour.

It can be said from these results of computations that the number density of atmospheric ice nuclei measured in a cold box is applied to real cloud (particularly the value 


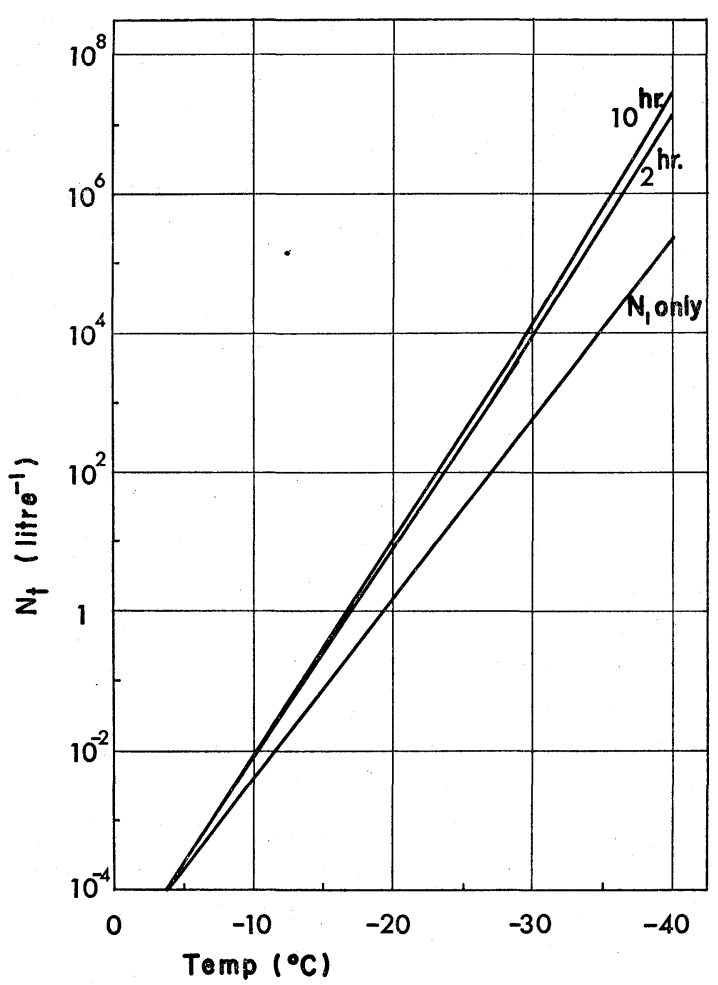

Fig. 5. Change with time in the temperature spectrum on the activation of atmospheric ice nuclei. Ordinate is the total number of atmospheric ice nuclei activated under the cooling at warmer temperature than the temperature shown by abscissa.

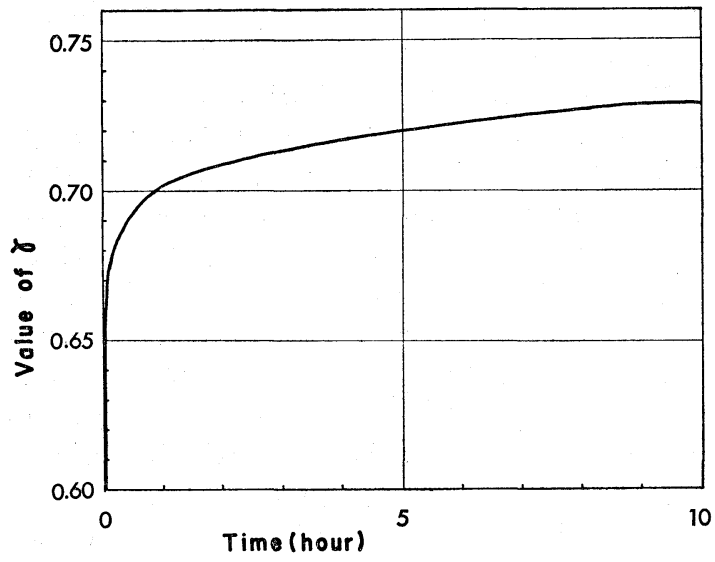

Fig. 6. Change with time in the value of $\gamma$.

obtained under the cooling at low temperature), the cooling time must be taken into consideration.

\section{Computational results on the number of atmospheric ice nuclei activated under the cooling at time-dependent temperature $(d T / d t \neq 0)$.}

In the previous chapter, treated were the cases in which cooling temperature is constant with time (that is, ice nuclei stay at constant level in cloud for a long time). In this chapter, the cases of the cooling at timedependent temperature such as those in upward air-current are computed. In these cases the change with time in the activation-probability of each ice nucleus must be taken into account because ambient temperature $T$ in equation (6) varies with time.

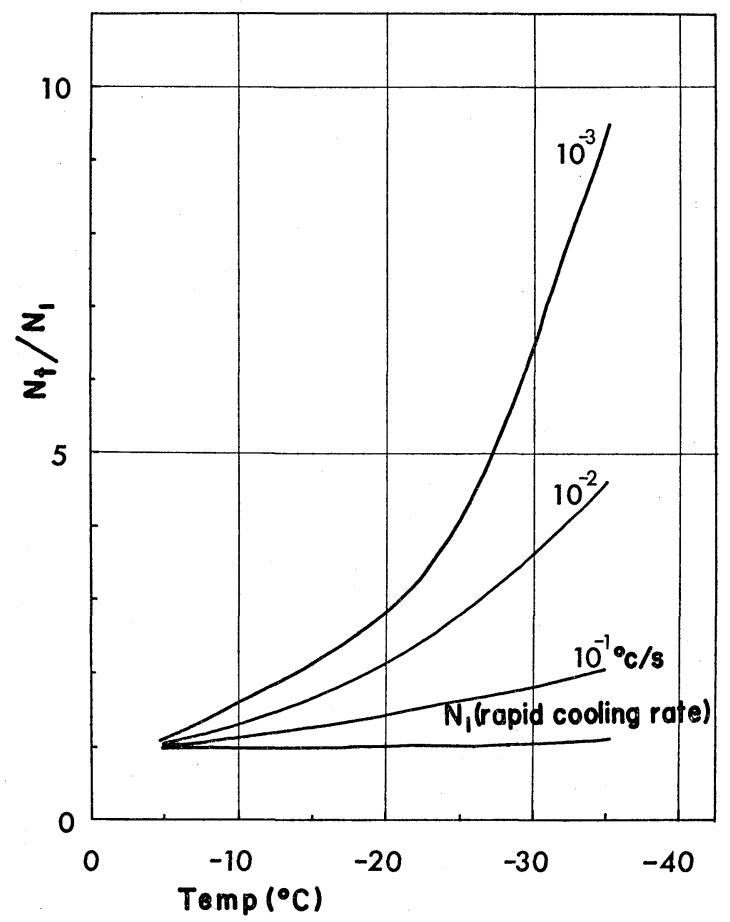

Fig. Number density of atmospheric ice nuclei activated under the cooling at time-dependent temperature. Ordinate is the number density of ice nuclei which are activated under the cooling from $0^{\circ} \mathrm{C}$ to the temperature shown by abscissa. Figures besides curves mean cooling-rate.

The results of computations are summarized in Fig. 7. Ordinate is the number of atmospheric ice nuclei activated in air parcel of unit volume which was cooled from $0^{\circ} \mathrm{C}$ to the temperature indicated by abscissa with constant cooling rate. Figures besides curves 
are cooling rate. The value of ordinate is expressed by the ratio of total number $\left(N_{t}\right)$ of activated ice nuclei to $N_{1}$ (here $N_{1}$ is equivalent to the total number of ice nuclei activated under the cooling at very rapid cooling rate). The cooling rates of $10^{-3}, 10^{-2}$ and $10^{-1}{ }^{\circ} \mathrm{C} /$ sec correspond to the upward air current with vertical velocity of $0.14,1.4$ and $14 \mathrm{~m} / \mathrm{s}$ in the case of lapse rate of $0.7^{\circ} \mathrm{C} / 100 \mathrm{~m}$, respectively. It is made clear from the figure that the number of atmospheric ice nuclei activated in upward air current of the order of $10 \mathrm{~cm} / \mathrm{s}$ is 5 to 10 times as large as that in vertical air current of the order of $10 \mathrm{~m} / \mathrm{s}$, if both cases are compared at the same level (or temperature).

\section{Conclusions}

The influence of the time lag in the activation of ice nuclei on the number of ice crystals in cloud were numerically studied.

Following conclusions were obtained; the increase with time in the number of activated atmospheric ice nuclei is remarkable particularly in the case of the cooling at low temperature. In applying the number density of atmospheric ice nuclei measured in a cold box to real cloud, the cooling-time must be taken into account particularly in the case in which nuclei are cooled at lower temperature than $-25^{\circ} \mathrm{C}$. The total number of ice nuclei activated for a few hours under the cooling at $-30^{\circ} \mathrm{C}$ to $-40^{\circ} \mathrm{C}$ is 10 times as large as that for 1 minute. However, in the case of the cooling at warmer temperature than $-20^{\circ} \mathrm{C}$, the number of activated nuclei is at most 2 to 3 times as large even after 10 hours as that after 1 minute.

Therefore, activated atmospheric ice nuclei do not increase with time so much in the cloud with warmer cloud-top temperature than $-20^{\circ} \mathrm{C}$, even if ice nuclei stay near the cloud top for a very long time. If the larger number of ice crystals than expected from that of atmospheric ice nuclei measured in a cold box is found in such a cloud, it may be originated from the accumulation of ice crystals in a region due to the interaction between airflow and the trajectories of ice crystals, from the ice crystals which fell without evaporating out from higher level where many ice nuclei can be activated, or from the mechanism of dropfreezing due to ice splintering suggested by Köenig and Braham.

Further it has been concluded that the number of ice nuclei activated in upward aircurrent with vertical velocity of the order of $10 \mathrm{~cm} / \mathrm{s}$ is 5 to 10 times as large as that in vertical air current of the order $10 \mathrm{~m} / \mathrm{s}$, if both numbers are compared at the same level.

\section{Acknowledgements}

The author wishes to express his hearty thanks to Prof. K. Isono and Prof. M. Komabayasi of Nagoya University for their useful suggestions and discussions.

\section{References}

Braham, R.R., Jr., 1964: What is the role of ice in summer showers? J. atmos. Sci., 21, 640-645.

Dunning, W.J., 1955 : Theory of crystal nucleation from vapor, liquid and solid systems. In "Chemistry of the Solid States" ed. W. E. Garner, Butterworths, London.

Fletcher, N.H., 1958: Time lag in ice crystal nucleation in the atmosphere, Part 2 Theoretical. Bull. Obs. Puy de Dome, 11-18.

Fletcher, N.H., 1962: The Physics of Rainclouds, Cambridge Univ. Press, 386.

Koenig, L. R., 1963: The glaciating behavior of small cumulonimbus clouds. J. atmos. Sci., 20, 24-47.

Koenig, L.R., 1966 : Numerical test of the validity of the drop-freezing/splintering hypothesis of cloud glaciation. J. atmos. Sci., 23, 726-740.

Mason, B. J., and J. Maybank, 1960: The fragmentation and electrification of freezing water drops. Quart. J. Roy. meteor. Soc., 86, 176-186.

Mossop, S.C., 1963: Atmospheric ice nuclei. Zeit. f. angew. Math. u. Phys., 14, 456-486.

Takeda, T., 1968: Solid precipitation in supercooled cloud, Part 1-Freezing of a super-cooldd water drop due to the collision of ice crystals-. $J$. meteor. Soc. Japan, 45, To be published.

Takeda, T., 1968: Solid precipitation in supercooled cloud, Part 2 -Growth of solid precipitation particles-. J. meteor. Soc. Japan, 45, To be published.

Vonnegut, B., 1949: Nucleation of supercooled water clouds by silver iodide smokes. Chem. Rev., 44, 277-289.

Warner, J., and T.T. Newnham, 1958: Time lag in ice crystal nuclertion in the atmosphere, Part 1 Experimental. Bull. Obs. Puy de Dome, 1-10. 


\title{
自然水晶核活性化のおくれが雲内の水晶数に及ぼす影響
}

\author{
武田喬男
}

(名古屋大学理学部水質科学研究施設)

自然水晶核活性化の怙くれが，雲の中の氷晶数に及ぼす影響を数値計算とより調べた結果，次の結論が得られた。 (1)活性化する自然氷晶核の数は氷晶核が冷やされる時間と共飞增すが その増加は特に $-25^{\circ} \mathrm{C}$ より低い温度で泠や された時䫓著である。 $-30^{\circ} \mathrm{C} \sim-40^{\circ} \mathrm{C} て ゙$ 冷やされた時活性化する自然水晶核数は, 数時間後には， 1 分後まで飞活 性化した数の 10 倍にす達する。しかし， $-20^{\circ} \mathrm{C}$ より高い温度で冷やされた場合に活性化する自然水晶核数は，10 時間後であ 1 分後までのせいぜい 3 倍にすぎない。( 2$) 10 \mathrm{~cm} / \mathrm{s}$ 程度の上年気流内で活性化する自然水晶核数は, 同じ 高度で比べると, $10 \mathrm{~m} / \mathrm{s}$ 程度の上昇気流内で活性化する自然水晶核数の数倍である。 